\title{
ENTREVISTA COM MARC POMERLEAU
}

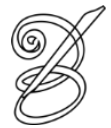 \\ Sônia Maria de Melo Fernandes Puttini ${ }^{i}$ \\ (Doutoranda em Estudos da Tradução - Université de Montréal/Canadá) \\ sm.de.melo.fernandes@umontreal.ca
}

M

arc Pomerleau é doutorando e professor substituto no Departamento de Linguística e Tradução da Universidade de Montreal, onde colabora com a revista de tradutologia Meta e com o Grupo de investigação em História da Tradução na América Latina (HISTAL), sob direção do professor Georges L. Bastin. Ele se interessa às questões de linguagem ligadas à Península Ibérica e à América Latina, especialmente línguas minoritárias e planejamento linguístico, assim como às relações entre história, política, identidade e tradução. Marc é tradutor profissional há mais de dez anos e membro da Ordem dos Tradutores do Quebec (OTTIAQ). Como tradutor juramentado, é especialista em tradução de documentos oficiais do espanhol, português e catalão para o francês. Nesta entrevista, Marc nos conta um pouco sobre sua experiência como tradutor no Québec e como pesquisador em tradutologia.

Você poderia falar um pouco sobre seu percurso profissional? Pra começar, como se interessou pela tradução?

MARC POMERLEAU: Quando comecei os estudos universitários, inicialmente não pensei em fazer tradução. Em geral, estava interessado em línguas. Então fiz uma licenciatura em Estudos Latino-americanos e Caribenhos, na Universidade McGill. No programa era obrigatório fazer espanhol e opcional português. Decidi fazer os dois. Ainda nesse programa, fiz um curso de um ano no México e só então, depois que já tinha um bom espanhol, é que pensei em fazer tradução. Queria fazer algo com o espanhol e a Universidade de Montréal era a única em Montréal (agora também há a possibilidade de se fazer na McGill) a oferecer o programa de tradução espanhol-francês, com duração de um ano. Terminei o curso, em 2002, e pouco tempo depois comecei a trabalhar em uma agência de tradução, com textos variados. 
Você já tinha traduzido alguma coisa antes de começar o curso de tradução?

MARC POMERLEAU: Antes do curso, eu já tinha alguns anos de experiência como guia turístico, fazendo excursões nacionais com clientes hispanófonos. Então fazia muita interpretação do francês ou do inglês para o espanhol. Muitas vezes em lugares turísticos ou em restaurantes, pois poucos falavam francês ou inglês. Então o primeiro contanto foi por meio da interpretação. Tradução de textos escritos foi realmente depois, na agência de tradução onde acabei ficando pouco tempo.

\section{E seu percurso como tradutor juramentado?}

MARC POMERLEAU: Depois do trabalho na agência comecei a fazer tradução pra uma senhora que trabalhava em Ottawa e tinha vários contatos com o governo canadense. Trabalhei com esses projetos variados por quase nove anos. Nesse tempo, passei um ano em Portugal pra melhorar meu português e fazer uns cursos, e de lá continuei a traduzir à distância. De volta ao Quebec, quando comecei o doutorado decidi parar com esse trabalho, porque queria estudar tempo completo. Além disso, tinha muita pressão, era muito

210 estressante, pois o tempo pra entrega das traduções era muito curto, às vezes tinha poucas horas pra terminar um projeto. Quando voltei de Portugal, em 2004, decidi fazer o D.E.S.S $S^{\mathrm{ii}}$. em tradução na Universidade McGill. No final, com a combinação dos dois diplomas (da Universidade de Montréal e da McGill), pedi a entrada na Ordem dos Tradutores do Quebec ${ }^{\mathrm{iii}}$

Quais são os pré-requisitos/formação necessária pra ser tradutor da Ordem no Quebec?

MARC POMERLEAU: A forma mais comum de se entrar é com uma formação (bacharelado ou licenciatura) de 90 créditos. Mas também é possível combinar certificados de 30 créditos que ao final resulte nos 90 exigidos pela Ordem. De qualquer forma, não é rápido pra entrar. Temos que montar e apresentar um dossiê com trechos de textos traduzidos. É preciso ter cartas de referências de clientes que atestem o número de palavras traduzidas e a qualidade da tradução. Antes tinha um exame pra entrar, mas agora é por meio de dossiê. É bastante complicado montar o dossiê, porque eles não aceitam qualquer tipo de texto. Então no meu caso, mesmo com o certificado em espanhol-francês não pude pedir a entrada com essa combinação, porque só pude comprovar os textos de inglês-francês. Com o tempo, depois que você já é tradutor da Ordem, fica mais fácil pra acrescentar outras combinações porque você não precisa montar outro dossiê, basta enviar os trechos de traduções realizadas. Então pouco a pouco comecei a juntar trechos em espanhol e um ano depois eles aceitaram acrescentar a combinação espanhol-francês ao meu dossiê. A partir daí, comecei a traduzir bem mais. Quase todos os membros da Ordem têm a combinação inglês-francês, então ter algo a mais 
faz toda a diferença porque não há muitas opções para os clientes potenciais. Com o espanhol, por causa do alto número de imigrantes, estudantes falantes do espanhol que precisam traduzir histórico escolar, diplomas e outros documentos oficiais quando chegam ao Quebec, o aumento de traduções foi significativo. A partir desse momento, me dei conta de que vale muito a pena ser tradutor da Ordem. Financeiramente o retorno é muito positivo. Por isso, comecei a juntar trechos para o português, que hoje também faz parte do meu dossiê da Ordem. Há mais ou menos um ano, depois que terminei um módulo em estudos catalães na Universidade de Montréal, acrescentei também a combinação catalão-francês. São poucos os tradutores juramentados que trabalham com o português, e com o catalão somos somente dois. Atualmente, $90 \%$ das traduções que faço são de documentos oficiais.

\section{Há outras formas de se tornar membro da Ordem?}

MARC POMERLEAU: Sim. Se a pessoa tiver um diploma como linguística, literatura, ou algo parecido, mais a comprovação de 5 anos de experiência é possível também. A Ordem tem um programa de aconselhamento ('Mentorat') no trabalho de tradução para essas pessoas. Por um preço baixo, os estudantes também podem ser membros. Há muitas vantagens: acesso à revista da Ordem e aos cursos oferecidos por eles, que como membro-estudante sai bem mais barato que o normal. Vale a pena!

Mudando um pouco o rumo da conversa... Você já era tradutor quando decidiu fazer mestrado e doutorado e investir também na carreira de pesquisador/professor. O que te levou a tomar essa decisão?

MARC POMERLEAU: Como já trabalhava há muito tempo como tradutor, desde o primeiro certificado, e em geral trabalhava em casa, decidi voltar a fazer aulas para aprender coisas novas, melhorar a prática, estudar outras línguas e pra fazer mais contatos. O trabalho do tradutor é muitas vezes solitário. Bom, além disso, a universidade sempre proporciona um grande estímulo intelectual. Então comecei a estudar linguística, fiz curso de árabe, história da língua, mas depois de um tempo queria algo além dos cursos de primeiro ciclo. Por isso comecei a pensar no mestrado, algo que antes nunca tinha imaginado fazer. Queria aprofundar meus conhecimentos. Não fiz mestrado profissional ${ }^{\text {iv }}$, porque eu já fazia tradução todos os dias. Decidi então pelo mestrado voltado pra a pesquisa. Achei que poderia ser interessante fazer algo sobre tradução, sem necessariamente ter que fazer tradução. Terminei o mestrado em 2011 - fiz o curso em tempo parcial, porque trabalhava nos outros turnos - na Universidade de Montréal. Trabalhei, sob a orientação do professor Georges L. Bastin, com uma tradução francesa do Popol Vuh, um documento maia da Guatemala, e gostei muito da experiência. 
O que mudou na sua visão sobre a tradução depois que você começou o mestrado e o doutorado?

MARC POMERLEAU: Foi interessante porque eu não tinha muitos conhecimentos teóricos sobre a tradução, tinha feito poucos cursos antes. Com o mestrado, comecei a perceber o lado social, histórico e político da tradução, e isso é algo de que gosto muito. Agora no doutorado, apesar de gostar bastante do tema do mestrado, quis trabalhar com algo que me tocasse mais, pois é um caminho mais longo. Gosto muito de trabalhar com línguas minoritárias, então depois de terminar o módulo do catalão, escolhi pesquisar sobre o papel da tradução no processo independentista da Catalunha, o que possibilita analisar esse lado político da tradução. Também acho que me chamou a atenção o fato de ser uma situação política parecida com a do Quebec (são casos diferentes, mas há muitas semelhanças como a ideia de um país dentro de um país). Com os últimos acontecimentos políticos catalães, o referendo que acontecerá em novembro, começaram a aparecer muitas traduções feitas pela sociedade civil pra explicar a situação sócio-política, histórica e linguística da Espanha e da Catalunha para o mundo. Acho muito interessante esse papel da tradução como ferramenta de difusão de ideias, de sensibilização, de propaganda, às vezes de manipulação, etc. É interessante ver os sites 212 multilíngues que estão sendo produzidos por essas pessoas. Há uma teoria sobre o multilinguismo que diz que as pessoas que vêm de uma comunidade de língua minoritária são mais abertas, mais sensíveis às línguas. Em parte também acho que é por isso que eles traduzem. Isso tudo é muito interessante e gostaria de saber mais sobre como eles utilizam a tradução nesse processo. Pode-se ver isso também como uma estratégia política ou paradiplomática, pois é a sociedade civil agora que está encarregada de fazer a diplomacia internacional. Bom, é sobre isso que vou falar no Brasil na Semana do Tradutor, de São José do Rio Preto, e no III Seminário de História da Tradução, na Universidade de Brasília, em setembro e outubro respectivamente. A ideia é falar sobre tradução e política e também sobre tradutores migrantes erradicados na Catalunha. Há um livro interessante, intitulado "Ajudeume", de uma brasileira que mora lá e escreveu sobre sua experiência - a visão de uma brasileira sobre a vida na Catalunha, em geral, e sobre a relação dos imigrantes com a língua catalã, em particular - que reflete a visão de muitos estrangeiros que moram por lá. Pretendo tocar um pouco em todos esses pontos.

Além dos seminários, você vai dar um curso de extensão na Universidade de Brasília. Qual é seu objetivo, seus interesses em relação ao curso, ao Brasil, à Universidade de Brasília?

MARC POMERLEAU: A primeira ideia é de uma troca, dar e receber ao mesmo tempo, compartilhando minhas experiências como tradutor profissional, também falar da minha cultura e da minha língua e receber informações dos alunos e das experiências deles com a 
tradução, a língua e a cultura brasileira, tudo isso por meio da tradução. Pretendo trabalhar com textos ligados à cultura do Quebec e a outras realidades francófonas, falar um pouco sobre a implantação do francês nas Américas, as diferenças em relação ao francês europeu, o porquê dessas diferenças, etc. Então faremos traduções de alguns clássicos do Quebec, alguns poemas, documentos históricos, políticos, etc. A ideia é mostrar um pouco, principalmente, da cultura quebequense por meio da tradução. O público-alvo pode ser alunos da tradução ou mesmo alunos do francês que querem conhecer outra realidade francófona e que tenham um nível intermediário (ou suficiente pra entender os textos) do francês. Seria como um curso de tradução geral. Então todos que conhecem um pouco de francês, estão convidados a fazer o curso. Pode ser interessante também para as pessoas que estão pensando em fazer intercâmbio no Quebec. Sabemos que o Brasil e o Quebec estão consolidando vários acordos no momentov ${ }^{v}$. Acho que é interessante começar a construir essa ponte entre a América Latina e a América do Norte, sobretudo com culturas mais periféricas e não só anglo-americanas, que também tem coisas muito interessantes, mas é muito "mainstream". É importante conhecer coisas diferentes. Os canadenses vão muito para o México, Cuba, etc., mas não tanto para o Brasil. Muitas pessoas estão interessadas, mas falta algo pra dar o primeiro passo. O Brasil não faz muita promoção aqui, mas talvez agora com esses acordos universitários tenhamos mais concretizações.

RECEBIDO EM 18/06/2014

ACEITO EM 01/07/2014

\footnotetext{
${ }^{\text {i }}$ Lattes Sônia Maria de Melo Fernandes Puttini. Disponível em: http://lattes.cnpq.br/0738911756894606

ii Diplôme d'études supérieures spécialisées.

iii OTTIAQ - Ordre des traducteurs, terminologues et interprètes agrées du Quebec.

iv No Quebec, em Tradução, como em outros cursos, pode-se escolher entre o mestrado profissionalizante ou voltado para a pesquisa (maîtrise professionelle ou maîtrise recherche).

v Brasil e Quebec estão consolidando vários acordos bilaterais de cooperação para facilitar o intercâmbio de estudantes e professores e para estimular o desenvolvimento científico. Por exemplo, a Universidade de Montreal e a Universidade de Brasília acabam de estabelecer um programa de cotutela em que os doutorandos poderão fazer uma parte da escolaridade em Montreal e outra no Brasil.
} 